\title{
WPS3447
}

\section{India's Public Health System How Well Does It Function at the National Level?}

\author{
Monica Das Gupta \\ Mdasgupta@worldbank.org \\ Development Research Group \\ The World Bank \\ Manju Rani \\ Consultant, Development Research Group \\ The World Bank
}

World Bank Policy Research Working Paper 3447, November 2004

The Policy Research Working Paper Series disseminates the findings of work in progress to encourage the exchange of ideas about development issues. An objective of the series is to get the findings out quickly, even if the presentations are less than fully polished. The papers carry the names of the authors and should be cited accordingly. The findings, interpretations, and conclusions expressed in this paper are entirely those of the authors. They do not necessarily represent the view of the World Bank, its Executive Directors, or the countries they represent. Policy Research Working Papers are available online at http://econ.worldbank.org.

We deeply indebted to the people at the Ministry of Health and Family Welfare and the National Institute of Communicable Diseases for their patience and generosity in carefully completing these questionnaires. We are also very grateful for helpful feedback from Shankar Acharya, Pranab Bardhan, Peter Berman, Stephen Howes, Krishna Jhala, K.P.Krishnan, Peter Miovic, Mick Moore, Ranjana Mukherjee, Lalit Nath, and Shahid Yusuf. 


\begin{abstract}
India has relatively poor health outcomes, despite having a well-developed administrative system, good technical skills in many fields, and an extensive network of public health institutions for research, training, and diagnostics. This suggests that the health system may be mis-directing its efforts, or be poorly designed. To explore this, we use instruments developed to assess the performance of public health systems in the United States and Latin America based on the framework of the Essential Public Health Functions identified as the basic functions that an effective public health system must fulfill. This paper focuses on the federal level in India, using data obtained from senior health officials in the central government.

The data indicate that the reported strengths of the system lie in having the capacity to carry out most of the public health functions. Its reported weaknesses lie in three broad areas. First, it has overlooked some fundamental public health functions such as public health regulations and their enforcement. Second, deep management flaws hinder effective use of resources, including inadequate focus on evaluation; on assessing quality of services; on dissemination and use of information; and on openness to learning and innovation. Resources could also be much better utilized with small changes, such as the use of incentives and challenge funds, and greater flexibility to reassign resources as priorities and needs change. Third, the central government functions too much in isolation and needs to work much more closely with other key actors, especially with sub-national governments, as well as with the private sector and with communities. We conclude that with some re-assessment of priorities and better management practices, health outcomes could be substantially improved.
\end{abstract}

\title{
Contents
}

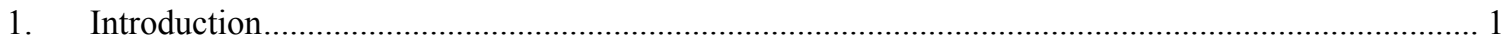

2. The Role of Public Sector Health Agencies in Assuring Public Health............................................. 2

3. Organization of Public Health Services at Central Government Level in India................................. 3

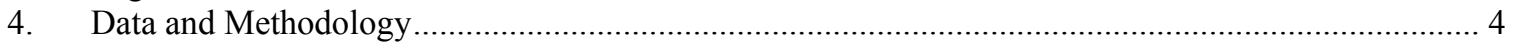

5. Results on Each Essential Public Health Functions and Its Indicators.......................................... 9

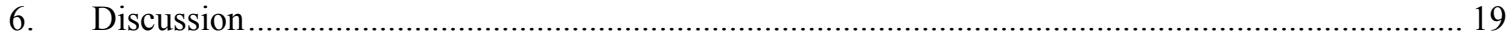

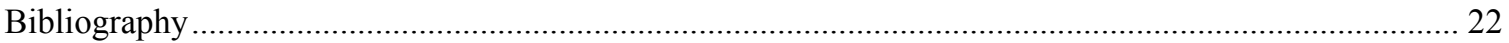

Appendix 1. Selected List of Central Health Institutions under the MOHFW's Department of Health...... 24 


\section{Introduction}

India has relatively poor health outcomes, despite having a well-developed administrative system, good technical skills in many fields, and an extensive network of public health institutions for research, training and diagnostics. This suggests that, beyond questions of funding shortages, we need to examine whether the public health system may be mis-directing its efforts, or be poorly designed. If so, it may also face problems in responding to the country's growing burden of non-communicable diseases. Most analyses have focused on issues related to the provision of medical services, or on specific issues such as immunization. We focus on understanding gaps in the performance of the basic functions that an effective public health system must fulfill, in which preventive and promotive activities play an important role.

Public health systems are conceptually distinct from medical services. They have as a key goal reducing a population's exposure to disease — for example through assuring food safety and other health regulations, vector control, and health education. These services are largely invisible to the public — typically, the public only becomes aware of the need for them when a problem develops (e.g., an epidemic occurs). ${ }^{1}$ Yet unlike most personal medical services, these services produce "public goods", and are of high priority for assuring good health outcomes. When public health systems falter people pay a high price in illness, debility and death, and if full-fledged outbreaks occur the economic costs can be very large: for example, the WHO (1999) estimates that the 1994 plague epidemic in Surat resulted in losses totaling $\$ 1.7$ billion.

Until recently, there were few tools for studying public health systems. A framework for analyzing public health systems as a whole has emerged from efforts to upgrade the US public health system, based on the "Essential Public Health Functions" (EPHFs). ${ }^{2}$ This framework is beginning to be used in other countries, developed and developing. ${ }^{3}$ Broadly, these "core functions" pertain to assuring health situation monitoring, disease surveillance; health promotion; public health regulations; community partnerships; development of policies and planning; access to and quality of services; human resource development; and reducing the impact of emergencies on health. Note that the emphasis is on functions, governance and organizational structures need to be examined separately.

We examine the functioning of India's public health system, and illustrate the strengths and weaknesses of the organizational context in which its component parts have to work. We use questionnaires based on the EPHF framework, designed for assessing the public health system in the US and Latin America, ${ }^{4}$ which we modified for India. This paper presents the data collected from federal-level respondents.

To provide a conceptual background for interpreting the results of our study, we begin with a brief discussion of the roles that public sector health agencies have to play in

\footnotetext{
${ }^{1}$ American Public Health Association (http://www.apha.org/ppp/science/10ES.htm).

${ }^{2}$ See US Centers for Disease Control n.d., also IOM, 1988; 2002a; 2003.

${ }^{3}$ See PAHO 2002, WHO 2002, Bettcher and others, 1998, United Kingdom (nd), and National Public Health Partnership (Australia) 2000.

${ }^{4}$ Public Health Functions Steering Committee 1994, and PAHO 2002.
} 
a public health system, and the roles of a central health agency in a large federated union of states such as India. This is followed by a brief description of the constitutional mandate and organizational structure of the central health ministry in India. We then describe the data and analytical methods used, and discuss the results for each EPHF individually. In the concluding section, we note that policy priorities have overlooked some fundamental public health functions, that the system has deep management flaws which hinder effective use of resources, and that it needs to do much more to collaborate with sub-national levels of government, as well as with other public and private agents and the communities it serves.

The results throw light on why the system is ineffective despite the considerable human and institutional resources at its disposal, and why in the absence of some systemic reform it is likely to prove difficult to improve the functioning of a specific service or program in isolation.

\section{The Role of Public Sector Health Agencies in Assuring Public Health}

Public health outcomes are influenced by a wide range of factors, many of them outside the direct ambit of public sector health agencies. Thus to assure good health outcomes, health agencies have to engage continuously with a wide range of actors through advocacy, coordination, and monitoring and oversight. This includes building, inter alia:

- intra-sectoral coordination between different actors in the public health agencies (e.g., to promote adequate flows of information and support, and to ensure consistency in policy and practice across programs, levels and jurisdictions);

- coordination with local governments - who often have primary responsibility for implementing public health regulations, and for many aspects of environmental sanitation;

- intersectoral coordination with other public agencies whose work impinges on health outcomes, for example school health or appropriate drainage in irrigation systems

- coordination with the private sector, especially with private health practitioners - at least for disease surveillance and supplying standardized care for diseases such as TB and STDs; and

- continuous partnership with communities, to build public demand for better health outcomes, raise awareness of the need to monitor local programs and policies, and alter personal health behaviors.

Depending on their level, health agencies have somewhat different roles to play. In a large federated union of states such as India or the United States, the central government health agency's role has relatively little to do with direct service provision. Their role is to facilitate the system's overall functioning through stewardship, advocacy, and support to sub-national levels who are more directly involved in service provision. ${ }^{5}$ These roles have been spelled out for the United States (Box 1). ${ }^{6}$ As discussed below, the MoHFW has the advantage of enormous financial leverage to help shape health outcomes.

\footnotetext{
${ }^{5}$ As VHAI (1997) puts it, the main objective at the central level should be to facilitate effective and efficient administration by the states, and local health authorities.

${ }^{6}$ Recent concerns with bio-terrorism have raised concerns that the US system is too federated. See for example Turnock and Atchison 2002.
} 
Box. 1 The Obligations of the United States' Federal Health Agency (IOM 1988:9):

- Support of knowledge development and dissemination through data gathering, research and information exchange

- Establishment of nation-wide health objectives and priorities, and stimulation of debate on interstate and national public health issues

- Provision of technical assistance to help states and localities determine their own objectives and to carry out action on national and regional objectives

- Provision of funds to states to strengthen state capacity for services, especially to achieve an adequate minimum capacity, and to achieve national objectives, and

- Assurance of actions and services that are in the public interest of the entire nation such as control of AIDS and similar communicable diseases, interstate environmental actions, and food and drug inspection.

\section{Organization of Public Health Services at Central Government Level in India}

\section{The constitutional role of India's central ministry of health}

According to India's Constitution, services are divided into "lists" which specify who is responsible for them and empowered to pass legislation on them: the Union list for the Central (federal) government, the State list, and the Concurrent List for tasks deemed the shared responsibility of the Central and State governments. Union laws override those made by the states for items in the concurrent list. The health-related provisions in the union list relate to port quarantine, research, and scientific and technical education. The concurrent list includes 'prevention of the extension from one State to another of infectious or contagious diseases or pests', and other issues with wider national ramifications such as food and drugs, family planning, medical education, and vital statistics (Gupta, 2003) ${ }^{7}$.

All other public health and environmental sanitation services are supposed to be the exclusive responsibility of states. However, the center exercises a great deal of power through fiscal control. Post independence India has had a tradition of centralized planning and policy making and decentralized implementation, and the relative financial strength of the central government - rooted in constitutional fiscal provisions - has given it significant leverage to determine the end use of its devolved funds to the states. Thus although public health is deemed a State subject, the perception of all but one of our state-level respondents ${ }^{8}$ was that health policy development and program design are carried out centrally.

Using its financial and political leverage, the central government can persuade the states to work towards specific health objectives and priorities, and provide the necessary

\footnotetext{
${ }^{7}$ The text of the concurrent list relating to health services is: 'Prevention of the extension from one State to another of infectious or contagious diseases or pests affecting men, animals or plants, adulteration of foodstuffs and other goods, population control and family planning, medical education and universities and vital statistics.' In practice, there is considerable overlap in the functions performed at the central, state and district level (Misra and others, 2001).

${ }^{8}$ Study carried out in Karnataka (See Das Gupta, Khaleghian and Sarwal 2003).
} 
technical support for this. An example of this is rural sanitation (in essence safe disposal of human excreta), which is listed as a 'state' subject but was largely neglected until the central government formulated a Central Rural Sanitation Program in 1984. This led the states to begin to implement rural sanitation schemes.

\section{Organization of Ministry of Health and Family Welfare (MoHFW)}

Headed by a cabinet-level health minister, the MoHFW has three independent departments each headed by a secretary: The Department of Health (DH), the Department of Family Welfare (DFW), and the Department of Indian Systems of Medicine and Homeopathy (DISMH). In addition, the MoHFW has 2 additional secretaries (both in DH), 8 joint secretaries and 30 officers of the rank of Director excluding technical advisors (Center for Policy Research, 1999). The Department of Health broadly deals with public health, medical services, medical education, food and drug standards, professional councils, and international aid and health research. The Department of Family Welfare is primarily responsible for family planning and maternal and child health. Although not specified in the business rules, the Department of Health traditionally deals with health policy and that of Family Welfare deals with rural health infrastructure (Misra et al 2001:197). The DISMH deals with all matters relating to alternative systems of medicine (i.e., Ayurveda, Siddha, Unani, Homeopathy, Naturopathy and Yoga).

The MoHFW's Department of Health is supported in its work by a vast network of autonomous research and training institutions which are spread all over the country but administratively under the central government (Appendix 1). These include the National Institute of Communicable Diseases (Delhi), which was set up as a center for disease control; the Central Bureau of Health Intelligence (New Delhi), several apex and regional training institutes, and specialized institutions such as the Central Food Laboratory and Central Drugs Laboratory. It also includes the Indian Council of Medical Research which is headquartered in New Delhi and has 6 Regional Medical Research Centers, and over 20 specialized research institutions and laboratories across the country. The Department of Family Welfare is supported by another network of institutions, and 18 research centers across the country. Besides these, the work of the MoHFW is supported by institutions run by other bodies, such as the central government's Council of Scientific \& Industrial Research which has institutions specialized in drug research and environmental engineering (Appendix 1).

\section{Data and Methodology}

\section{Data used}

The functioning of the Essential Public Health Functions (EPHFs) was measured using survey instruments adapted from those developed by the U.S. Centers for Disease Control and the Pan American Health Organization (PAHO, 2002) in their studies of public health systems in Latin American Countries ${ }^{9}$. Faced with a perceived crisis in the public health system, a committee headed by the Surgeon-General developed this EPHF

\footnotetext{
${ }^{9}$ The CDC had several iterations (we modified a semi-final iteration).
} 
framework and these instruments were subsequently designed to assess the performance of these EPHFs. In the United States, they have been used by individual states to identify the most pressing gaps in their public health services, and by the federal government to analyze patterns in states' service gaps which require broader policy responses (PAHO 2002: Chapter 12). It has been similarly used by the WHO in Latin America and East Asia (PAHO 2002, WHO 2003).

These questionnaires were modified for use in India, with inputs and feedback from experts and counterparts in India. The complete questionnaires can be accessed on the website http://www1.worldbank.org/publicsector/bnpp/Preventhealth.htm. We collected data from individuals separately, in a methodological departure from the CDC-PAHO approach of obtaining consensus responses from national and sub-national level respondents (PAHO 2002: 114). As a result, we are able to analyze separately the responses from different categories of respondents, which also permits analysis of how perceptions of functioning differ between different categories of respondents. ${ }^{10}$

The EPHF assessment questionnaires were completed by 119 respondents: 19 at the central level, 10 at state level, and 90 at district level. ${ }^{11}$ Here we present the results from the data collected in May-June 2003, from senior officials in the central MoHFW's Department of Health, and the National Institute of Communicable Diseases (NICD). The MoHFW is the main policy-maker in the national public health system, and the NICD is the MoHFW's primary public health agency. We selected the respondents from the main public health-related departments in each agency. Several visits were made if necessary to obtain the responses, so non-response was rare. The questionnaires were selfadministered, and responses were kept anonymous.

This study is exploratory in nature, and the conclusions that can be drawn from it are limited by its design and methodology. The EPHF assessment questionnaires are designed to elicit a self-evaluation of the public health system, from people who know the system well from within (PAHO 2000). It is not in any sense an external evaluation, nor are the questions of the "objective" sort typically asked in surveys. For example to assess an aspect of center-state collaboration, it does not ask an "objective" question such as how many meetings were held with sub-national health agencies last year. Instead it asks questions such as whether sub-national levels are provided with public health data, followed by more detailed questions to assess whether the data are made user-friendly, whether attempts are made to evaluate the use of data and modify their presentation to expand their potential use, etc.

The EPHF performance assessment questionnaires are designed to collect data from a group of people selected for their in-depth knowledge of a particular set of issues. This is quite different from large-scale surveys, which use large samples to catch infrequent events or combinations of factors. The EPHF approach is akin to the "polls of experts" that Kaufmann and others (2003) use to develop governance indicators. As they show, the reported perceptions of those well-placed to assess a given issue can lead to robust

\footnotetext{
${ }^{10}$ This is reported in the analyses which include the state and district-level responses. See Das Gupta, Khaleghian and Sarwal (2003), and Das Gupta and Rani (forthcoming).

${ }^{11}$ Additional data were collected on governance issues at state and district level, using other questionnaires.
} 
findings. Elsewhere, they point out that "for many dimensions of governance, subjective data is the only data that is even potentially informative", given that their functioning is almost impossible to measure directly (Kaufmann and Kraay 2004). Our data also show strong internal consistency in the responses to different types of questions, for example in showing clear areas of strengths and weaknesses which cut across many indicators and sub-questions. ${ }^{12}$ Also, there is broad agreement on issues between the responses from respondents at the national level, and those at the state and district levels. ${ }^{13}$

The nature of the instrument does not allow for internal cross-validation of responses - although some validation can be achieved by looking for patterns within the data, and by triangulating the study findings with the existing empirical evidence on similar issues. Moreover, the instrument only evaluates whether certain functions are performed or not, and not how well they are performed.

In principle, this kind of instrument has the potential for aggregated responses to either overstate or understate functioning, depending on how high respondents' expectations are regarding the service. High expectations and high standards will tend to lead to understatement of functioning, and low expectations to overstatement. Given the many administrative and other constraints on effective service delivery in India, it is likely that the respondents' expectations are low.

As a result of low expectations, negative responses are likely to be more informative than positive ones. For example (as we find below), the existence of any program on a particular EPHF may make respondents inclined to say that that function is being met and only closer questioning will reveal that it is only partially met. When a response is negative, it can be safely assumed that very little is being done on that issue.

Other potential sources of error include exaggerating performance or lack of familiarity with the issues. In India, officials face little pressure to exaggerate their performance, because there are few rewards or sanctions related to performance. If an official has recently been transferred to a division, they may be unable to respond fully to questions about his/her new tasks. The other side of this is that having the opportunity to serve in different divisions and participate in departmental meetings that cover many functions means that respondents have knowledge of a wider variety of functions than those currently in their charge. These potential errors are reduced by aggregating the responses.

\section{Deriving the scores}

The questionnaire is divided into sections: one section for each EPHF, with subsections for each indicator of that EPHF (Table 1). Each section begins by describing the services under this function, and each sub-section begins by describing the services specific to that indicator. This orients the respondent to the issues being addressed in different parts of the questionnaire. For each indicator, a series of questions and subquestions drill down on each issue (as illustrated in Tables 2 and 3).

\footnotetext{
${ }^{12}$ However, unlike their study, we do not use respondents with cross-national knowledge of the issues, and therefore our data cannot be used for cross-national comparisons.

${ }^{13}$ Das Gupta and Rani, forthcoming.
} 
Each question had a yes/no response. Each indicator was assigned scores ranging between 0 and 1 based upon the average of proportion of positive responses to the questions and sub-questions detailed under that indicator. The scores for constituent indicators are then averaged to calculate the score of the perceived performance for each EPHF.

Table 1. Scores (on a scale of 0-1) for Each Essential Public Health Function, and its Indicators*

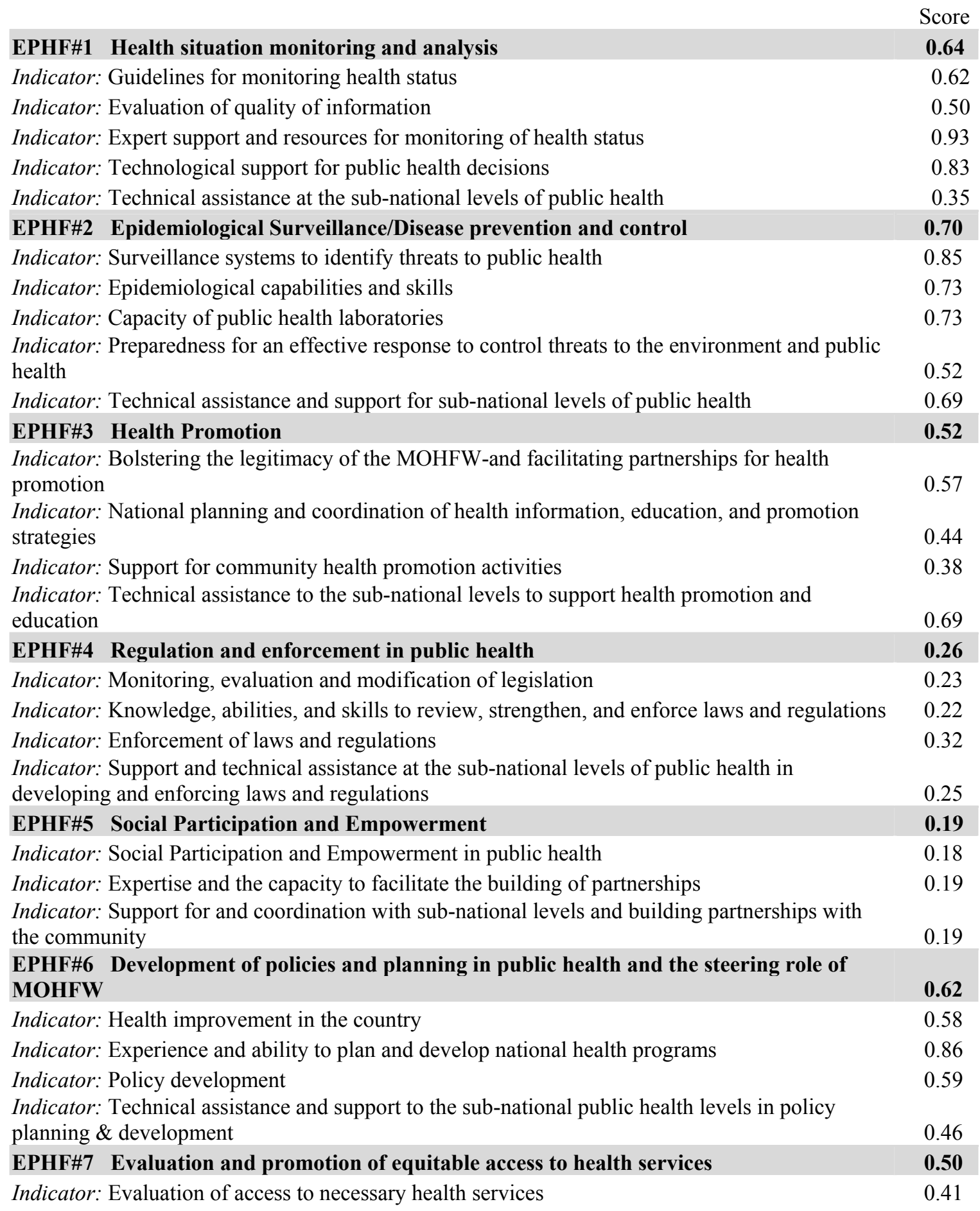


Indicator: Training and skill development to improve access to necessary health programs and services

Indicator: Advocacy and action to improve access to necessary health services

0.52

Indicator: Support and technical assistance for the sub-national levels of public health to promote equitable access to health services

EPHF\#8 Human resource development and training in public health

Indicator: Description of the public health work force

Indicator: Improving the quality of the work force

0.54

Indicator: Continuing education and graduate training in public health

Indicator: Enhancing human resources to ensure culturally appropriate delivery of services to the users

Indicator: Developing public health leadership

0.16

Indicator: Support for sub-national levels in human resources development

EPHF\#9 Ensuring the quality of personal and population-based health services

Indicator: Definition of standards and methods of evaluating the quality of population-based and personal health services

Indicator: Improving the quality of the health system and user satisfaction

0.30

Indicator: Systems for technology management and technology assessment to support public health decisionmaking

Indicator: Technical assistance and support to the sub-national levels to ensure the quality of health services

EPHF\#10 Research, development, and implementation of innovative public health solutions

Indicator: Development of a public health research agenda

0.64

Indicator: Development of internal research capacity

Indicator: Support for innovation and research in public health at the sub-national levels

EPHF\#11 Management capacity to organize health systems and services in public health

Indicator: Planning and evaluation in public health

Indicator: Evidence-based decision making in public health $\quad 0.54$

Indicator: Resource management in public health $\quad 0.61$

Indicator: Management of international cooperation on public health $\quad 0.73$

Indicator: Leadership and communication $\quad 0.54$

Indicator: Technical assistance and support for public health management at the sub-national levels

Indicator: Development of standards and guidelines that support emergency preparedness and disaster management

Indicator: Technical assistance at the sub-national level to support emergency preparedness and disaster management in health

*Note on the scoring: A series of questions and sub-questions with a yes/no response was asked on each indicator. The score for each indicator reflects the average of proportion of positive responses to the questions detailed under that indicator. The scores for constituent indicators are then averaged to calculate the score of the perceived performance for each EPHF. A score of 1 indicates that respondents stated that all the specific tasks on an indicator were performed, while a score of 0 indicates the converse. 


\section{Results on Each Essential Public Health Functions and Its Indicators}

The scores for each EPHF and their constituent indicators are shown in Table 1, and the summary scores for each EPHF are shown in Figure 1. The questions and subquestions on each indicator throw important light on the functioning of the public health system, but it would be very unwieldy to present tables with these detailed scores. A few are presented for illustrative purposes in Tables 2 and 3, but for the most part the detailed results have been summarized in the text. The figures in brackets in the text below refer to the score (on a scale of 0-1) for a particular question or sub-question.

Figure 1. Summary Scores for Public Health Functions at Federal Level, India (scores on a scale of $0-1$ )

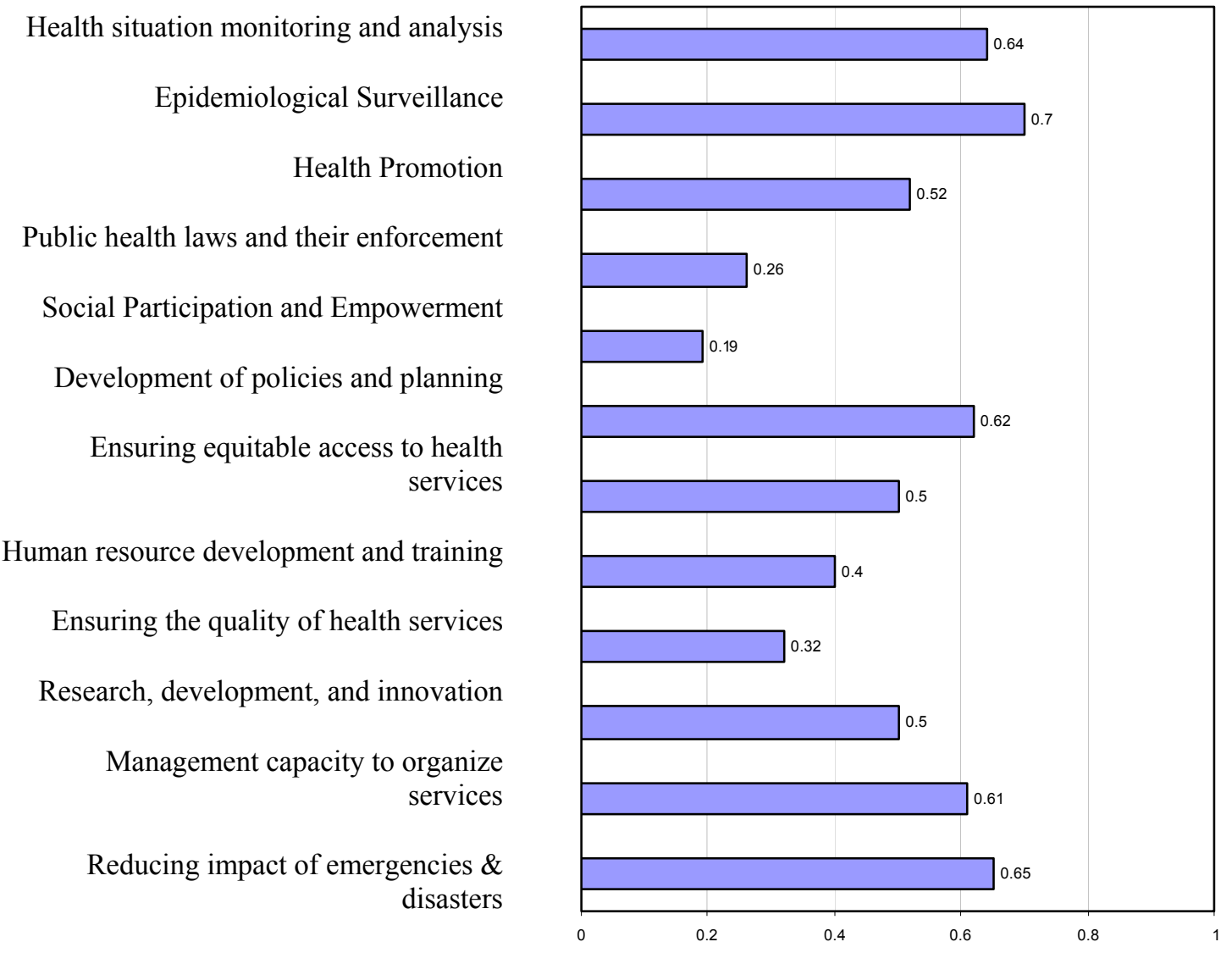

As noted above, the results presented here reflect the perceptions of the surveyed officials regarding the effectiveness of their agency's functioning, even though this is not specified throughout for reasons of avoiding repetition.

EPHF \# 1: Health Situation Monitoring and Analysis:

This function had a moderate overall score. There were strong reported strengths in having the expertise and resources for monitoring health status, and for technological 
support for decisionmaking. However, poor performance was observed in several areas critical for translating these resources into effective use. The MoHFW prepares health profiles, but these are deficient in data on important inputs for influencing health policies such as environmental risks (score $=0.26$ ). While the report is disseminated, the MoHFW does not regularly organize activities to explain the implications of the report to key decisionmakers, or evaluate how the reports are used (score $=0.26)$. The health profiles are not used to help communities prioritize their health problems.

The quality of the information is not adequately evaluated - the sub-questions reveal that performance is especially poor in reviewing data collection protocols periodically to evaluate whether they need updating, and in conducting periodic audits of the information system. Most startling is that most respondents felt that little consideration is given to suggestions from the MoHFW's own evaluation unit for improving data collection and measurement of the country's health status.

These and related lacunae in collecting and using health statistics are highlighted in the National Health Policy 2002:

"The absence of a systematic and scientific health statistics data-base is a major deficiency in the current scenario. The health statistics collected are not the product of a rigorous methodology. Statistics available from different parts of the country, in respect of major diseases, are often not obtained in a manner which make aggregation possible or meaningful" (section 2.19.1 National Health Policy 2002).

Technical assistance to sub-national levels is poor, which means that much of the benefits of health status monitoring are lost. Instead of being viewed essentially as data collecting agencies for the higher levels, state and local health authorities need to use the data to inform local decisionmaking. This makes it essential for higher levels to extend technical and other support to lower levels, and also carefully disseminate their findings to them in a user-friendly way.

\section{EPHF \# 2: Epidemiological surveillance/Disease Prevention and Control}

This function was scored fairly highly by respondents. The respondents perceived strengths to lie in the existence of a surveillance system to identify threats to public health, and having technical capabilities of various kinds: to develop written protocols aimed at identifying threats to public health, experience in basic sanitation; environmental health; conducting research on diseases, rapid epidemiological evaluation methods; rapid screening of high-risk populations; and conducting rapid environmental screening. They also perceived good capacity in the public health laboratories to support the government's diagnostic and research activities on health risks and threats.

In contrast to almost all the other EPHFs, technical assistance to sub-national levels received a moderate rating, perhaps because a national surveillance program has recently been developed. The MoHFW's system is perceived to be integrated with the subnational surveillance systems.

However, there are notable gaps in some crucial factors involved in translating these resources into outcomes. Firstly, the surveillance system is poorly designed, in that little 
effort is made to involve critical actors outside the public sector. In particular, half the respondents reported neglect of inputs from the private sector and NGOs - although private providers supply the bulk of ambulatory services in India (IIPS, 2002) and are therefore key to reporting diseases and responding to threats. This could account for the substantial under-estimation of mortality and morbidity noted by ICRIER (2001). Also, little effort is made to evaluate how information from the surveillance system is used by users internal or external to the MoHFW (score=0.37).

Secondly, preparedness for effective response to health threats received a mediocre score. The strong suit here is in having protocols and procedural manuals to guide rapid responses to emergency public health threats. However, the system's rapid response capacity is infrequently evaluated, and the results of the evaluation are poorly disseminated (score $=0.32$ ). Also lacking are formal mechanisms to recognize good performance by teams responsible for surveillance activities and for those responsible for emergency response systems (score $=0.32$ ). The surveillance systems are also not well adapted to epidemiological challenges such as mental health, risk factors for chronic diseases, occupational health, and the environment.

The absence of a comprehensive surveillance system, inadequate attention to use of information, and poor maintenance of emergency response systems hinder the ability to recognize early warning signals of disease outbreaks. As the National Health Policy 2002 notes, "The absence of an efficient disease surveillance network is a major handicap in providing a prompt and cost-effective health care system" [section 2.18.1].

\section{EPHF \# 3: Health promotion}

While the routine implementation of health promotion activities clearly falls to the states and the districts, the MoHFW has a stewardship role in developing standards and guidelines, identifying key areas where intense IEC action is required, cutting-edge research and providing technical assistance to the states. The Central Health Education Bureau, New Delhi has been set up precisely with this purpose.

However, this EPHF has a modest overall score. The strengths were perceived to lie in the existence of defined policies and goals, and setting priorities in line with the country's health status profile. Perceived weaknesses lie in the planning and implementation of strategies, and in support for community health promotion activities.

Much can be done to improve the effectiveness of health promotion. Specific weaknesses were perceived, including inadequate attention to evaluating programs and modifying them accordingly (score $=0.47$ ), and soliciting the views of end-users when evaluating health promotion programs (score $=0.32$ ). A major gap is the lack of incentives for good performance: for example through making national health promotion awards (score $=0.11$ ). Financing is provided for health promotion, but this is not done in ways which directly encourage good outcomes, such as providing competitive funds for health promotion projects $($ score $=0.21)$.

Support to sub-national levels is reportedly strong in this EPHF. This may reflect the fact that some strong health promotion efforts are in place for reproductive and child health programs under the high-priority national population control efforts directly 
financed by the central government. Other aspects of health promotion receive much less attention.

\section{EPHF \# 4: Regulation and enforcement in Public Health}

A good system of regulation is fundamental to successful public health outcomes. It reduces exposure to disease through enforcement of sanitary codes such that, for example, slaughterhouses are hygienically run, water is not exposed to contamination, and garbage is safely disposed. It ensures the timely follow-up of health hazards, and monitors the quality of medical services and products.

Unfortunately, the overall score for this EPHF is amongst the lowest of all (Figure 1). Similarly low scores span all the indicators: monitoring, evaluating and modifying legislation, skills to review and enforce laws and regulations, actual enforcement-related activities, and support to sub-national levels.

The sub-questions reveal specific lacunae in the system. Though there are written guidelines on public health enforcement procedures, almost none reported that there are mechanisms in place to encourage enforcement personnel to use their authority honestly and correctly (score $=0.05$ ). Regular in-service training is barely provided for enforcement personnel (score $=0.10$ ). Though respondents felt that the MoHFW has experience in drafting laws and regulations, further questioning revealed that it does not have personnel with the necessary knowledge of the necessary legislative and regulatory procedures. Almost all respondents stated that the MoHFW does not evaluate its capability to draft public health laws and regulations and enforce them.

There is devastatingly little attempt to build the partnerships without which it is simply not possible to have effective implementation of public health laws and regulations. The support of non-government stakeholders is barely sought in evaluating health laws and regulations (score $=0.21$ ). Support to sub-national levels is low, and even lower when it comes to supporting specialized personnel who deal with complex enforcement operations.

Concerted efforts are required to update the laws, make effective arrangements for their implementation, consult stakeholders, and increase public awareness of the existing laws and regulations and their enforcement procedures. Adequate trained manpower is needed. The status on enforcement should form an integral part of the health status bulletins of the national and sub-national levels of the government. At present, the discussion of health regulations in India tends to focus on deficiencies in mechanisms for quality control of medical services and products, while ignoring the burning need to update and enforcing sanitary codes and standards to reduce exposure to disease. ${ }^{14}$

\section{EPHF \# 5: Social Participation and Empowerment in Public Health:}

Raising public awareness and building social participation is critical for the success of a public health system. Amongst other things, it builds constituencies and public support for policies and programs, generates compliance with regulations, and helps alter

\footnotetext{
14 This can be seen even in the National Health Policy 2002, which makes little mention of public health regulations, while noting the need for regulating medical services in Section 2.16.1.
} 
personal health behaviors. Unfortunately, the overall score for this EPHF is the lowest of all (Figure 1), and this score applies across the sub-indicators: building social participation; capabilities to build partnerships, and support to sub-national levels.

Little effort is made to elicit information from communities to evaluate the quality of health services, for example through surveys, from local organizations, or community meetings (scores 0.05-0.21). Nor are evaluation results communicated to communities along with any resulting policy or program changes. More could be done to actively encourage community groups to participate in public health matters, and to facilitate the development and management of public health projects by community groups (scores $=0.42$ ).

In terms of capabilities to build partnerships, the MoHFW staff lack training in the creation of sustainable partnerships, especially in key skills such as support of coalitions, management of conflicts, and development of advocacy (score=0.10). The MoHFW does not systematically evaluate its partnership-building activities, or use these evaluations to improve its work (score $=0.05$ ). Little effort is made to help sub-national levels organize community participation, or partnerships to improve community health (scores 0.21 $0.26)$.

This poor record may be because direct interaction with communities is believed to lie outside the scope of the central government health agency. In the process, opportunities are lost for obtaining grassroots feedback for policy-making, for demonstrating how to build partnerships with the public, and above all for playing the advocacy role necessary for a central health agency. The national health agency needs to define a clear policy on social participation and how to operationalize it.

\section{EPHF \# 6: Development of Policies and Planning in Public Health and the Steering role of the MoHFW}

The overall score for this EPHF is moderately high. The MoHFW has considerable strengths in taking leadership. Most respondents stated that it has the competence to plan and develop national health programs, and that it develops plans with clear goals; identifies individuals and organizations to achieve those objectives; and develops performance indicators to measure the achievement of these objectives.

However, flaws in forming and exercising the necessary partnerships weaken the implementation of these plans. Although almost all respondents stated that the MoHFW assumes leadership in developing the public health policy agenda, few said that it shares this agenda with interested stakeholders such as unions, consumer associations, professional associations, community organizations, or NGOs. It does not ensure wide participation in defining and discussing policy options. Little is done to identify and engage potential partners in achieving health improvement, or to involve stakeholders in defining goals and associated measurement indicators. Nor does the MoHFW inform decisionmakers and the general public of the likely consequences of implementing public health policies. These responses indicate that the MoHFW needs to focus much more on its advocacy roles, building awareness and support for public health policies.

EPHF \# 7: Evaluation and promotion of equitable access to health services 
Ensuring equity in access and utilization of health services is one of the primary justifications for governments to provide clinical health services, which could otherwise be considered private goods. In particular, this ensures that people with communicable diseases (notably TB and STDs) can be given high-quality standardized treatment regardless of ability or willingness to pay, thereby also protecting the public health by cutting disease transmission to others.

The MoHFW can play an important role by laying down guidelines and by carrying out periodical evaluations to ensure equity in access to health care. However, this EPHF has a modest overall score, and modest to low scores across all the indicators.

Most respondents stated that the MoHFW has personnel who specialize in mass media communications and community outreach programs, and also personnel trained in monitoring and evaluation of utilization patterns of different aspects of health services. Utilization of this capacity is less strong: national evaluation of access to necessary health services are carried out, but with inadequate focus on key issues such as access to PHC services, access to personal services such as STD clinics or tuberculosis care, and on identifying barriers to accessing health care services (scores $=0.53$ ). There is a similarly indifferent record of using results from the evaluations to promote equitable access or to introduce changes to outreach activities.

Once again, weaknesses in implementation arise from lack of partnerships. This is true even with other public sector agencies: for example, most respondents stated that evaluations are not performed in cooperation with other governmental entities outside the health sector, or with non-governmental entities. Little is done to address gaps in access to health services by providing incentives to health care providers to improve access to their services by the marginalized or poor (score $=0.21$ ). Also poor is the reported record of encouraging sub-national authorities and community groups to develop innovative solutions to promoting equitable access to health services.

\section{EPHF\# 8: Human resource development and training in public health}

There are several shortfalls which need to be addressed in the development of human resources for public health services. Respondents reported especial weaknesses in developing public health leadership and in working with academic institutions to provide training in public health for MoHFW staff — as well as in supporting sub-national levels in their human resource development.

This EPHF received one of the lowest overall scores. This is despite many strengths: for example, almost all respondents stated that the MoHFW periodically evaluates the current composition of the country's public health work force, determines the number of public health workers required, and defines the job descriptions and skills needed for all categories of health workers. Weaknesses lie, inter alia, in workforce planning: projecting future workforce needs, and developing strategies for meeting these needs (scores 0.37-0.42).

For improving the quality of work force, most respondents stated that there are policies in effect for training staff, and to encourage staff to participate in continuing education opportunities. However, only around half the respondents felt that the MoHFW encourages academic institutions to develop basic public health curricula tailored for 
different categories of health staff, and to offer programs that meet the needs of MoHFW staff. Almost none stated that feedback is sought from staff about their training, and to encourage training institutions to modify their programs accordingly.

Other aspects of human resource management appear to be neglected. Few stated that the MoHFW periodically evaluates the effectiveness of its recruitment and retention policies. Less than half felt that there was an effective performance evaluation system for public health workers. Almost none stated that efforts are made to develop public health leadership, and none stated that the MoHFW seeks to actively identify potential leaders and support their leadership development. Support to sub-national levels on human resource development issues is also poor. Clearly, policies need to be better defined for assessing workforce needs and for supporting its development.

\section{EPHF \# 9: Ensuring the quality of personal and population-based health services}

The activities in this EPHF received a poor overall score (0.33), and similarly poor performance is evident across all the indicators. Clearly defined quality standards need to be not only formulated but also implemented, to improve service delivery.

All respondents reported that the MoHFW regularly evaluates the quality of public health services (such as immunization, PHC, TB control, etc.). Most reported that the evaluations use predefined service standards, but few stated that the inputs of subnational levels of government and non-governmental organizations are actively sought in developing these standards.

Efforts to improve the quality of the health system and user satisfaction received a low overall score, despite organizational strengths in planning. The score is low because of weaknesses such as little reported use of key inputs, such as the results of the measurement of user satisfaction, to shape policies. Although most respondents reported that user-satisfaction with population-based health services is regularly evaluated, few stated that efforts are made to get confidential feedback from service users. Moreover, few stated that the evaluations are carried out in cooperation with key decisionmakers involved in these services, or that the results are communicated to all participants in the process.

These lacunae need to be addressed to improve service quality. And importantly, much needs to be done to increase support to sub-national levels for ensuring the quality of health services, which is currently rated very low.

\section{EPHF\# 10: Research, Development, and implementation of innovative public health solutions}

The central government needs to not only do research, but collaborate in this with domestic and international institutions. It needs also to disseminate research and policy findings from across the world, spelling out their applications for specific problems or regions of the country. And the results of research need to be fed back into policy and programming.

The MoHFW has an extensive infrastructure for this, with several national research institutions directly under it (Appendix 1). This is reflected in the respondents' perception of the MoHFW's strengths in this EPHF, notably in having developed a research agenda, 
established procedures to review and approve research, access to a good public health research network, and acting as an advocate for public health research.

Nevertheless, this EPHF received the modest overall rating. This is because of some striking lacunae in actions taken, which detract from the effective deployment of these strengths. For example, most respondents stated that progress in carrying out the R\&D agenda is periodically evaluated, but only half felt that the results are adequately communicated even to those involved in carrying out the agenda. Even fewer felt that MoHFW programs and policies are modified in light of findings from MoHFW-funded studies, or from the international published literature. Most disconcertingly, support to sub-national levels is very weak, and almost none stated that sub-national levels are adequately advised on the meaning of research findings (score 0.16). This means that the benefits of research are not being passed on to those responsible for planning and implementing direct service provision.

EPHF \# 11: Management capacity to organize health systems and services in public health

The MoHFW has many important perceived strengths in performing this function most respondents stated that it has the capacity and resources to collect and evaluate information from various sources, though fewer respondents felt that this information is used to continually improve services. There was widespread agreement that the MoHFW ensures that it has the necessary resources (financial, technical and human) to carry out its functions, has a continuous monitoring system, and a high level of international cooperation.

However, the effectiveness of this function is hampered by some key weaknesses (Table 2b). The MoHFW is perceived to have the competencies necessary to exercise leadership in the health system, but this breaks down on detailed questioning, showing that these competencies are deficient in conflict management, leadership development, and development of teamwork. The MoHFW has a clearly articulated organizational vision, but is less strong at exercising its leadership in a way that guides the health system towards that vision. 
Table 2. Illustration of how initially positive assessments of a function change with detailed questioning (Scores on a scale of $\mathbf{0 - 1}$, see note for Table 1)

Table 2a (from EPHF\#6)

Score

The MOHFW periodically evaluates its current and potential partners in both the public and private sectors to determine the extent of their support and commitment to the development, implementation, and evaluation of the national process to improve health

If yes

- Do results from the last evaluation indicate that partners are well-identified and prepared to accept responsibility?

- Did results from the last evaluation help to develop a model for interaction?

The MOHFW ensures wide participation in defining and discussing policy options.

If yes, do these activities include:

- Preparing summaries to explain public health subjects of national importance?

- Organizing meetings to hear public testimony and concerns?

- Communicating with national boards or advisory committees responsible for policy development?

Table 2b (from EPHF\#11)

! The MOHFW has the competencies necessary to exercise leadership in the health system

0.90

If yes, do these competencies include:

- Inter-organizational relations

- Conflict management

- Leadership development

0.21

- Development of teamwork

- Organizational development

! The MOHFW has a clearly articulated organizational vision.

! The MOHFW exercises its leadership to guide the health system toward that vision

0.53

Table 3 illustrates how systems are in place, which could with some modification be made much more effective. The MoHFW has the capacity for assembling and processing data for the planning process. However, this does not result in adequate information on key variables in the planning process, such as cost analysis, existing resources in the health market, quality of services, and utilization of services. Besides, inadequate effort is made to make this information available to sub-national levels, or to give them technical assistance in the use of these data.

Several other factors also make it difficult to improve performance: for example, only around half the respondents reported that the MoHFW has defined standards of excellence, well-defined performance measurements, or ability to effectively communicate its policies and plans. 
Table 3. Strengths and Weaknesses of the System: Small Changes could Increase Effectiveness

\section{Indicator 11.2: Evidence-based Decisionmaking in Public Health}

! The MOHFW has the capacity to collect and integrate data from internal and external sources 0.74

! The MOHFW has an information systems to process the collected data and build comprehensive databases to be used in the planning process

If yes, does the processing of data result in information on:

- Demographic characteristics of the community 0.37

- Existing resources in the health market 0.32

- Cost analysis 0.26

- Utilization of services $\quad 0.53$

- Quality of services 0.53

! The MOHFW has sufficient expertise to use this information for evidence-based decisionmaking 0.68

! The MOHFW ensures that this information is made available to all groups involved in the decisionmaking process - including policymakers, community groups, academics etc. $\quad 0.58$

$\begin{array}{ll}\text { ! The MOHFW ensures that this information is made available to sub-national levels. } & 0.47\end{array}$

! The MOHFW provides technical assistance to sub-national authorities in the use of this data $\quad 0.37$

\section{EPHF \# 12: Reducing the impact of emergencies and disasters on health}

This EPHF is one of the quintessential functions of a public health system, and the detailed questions indicate that its overall effectiveness is fairly high. There was widespread agreement that the MoHFW has many strengths for this function. These include having a national plan, and a unit in the MoHFW with its own assigned budget. Other key strengths are that the MoHFW is in a position to direct the entire health system, develops standards and guidelines, coordinates with other agencies or commissions involved in disaster management.

Support to sub-national levels is also rated more highly by respondents than for most other EPHFs. All agreed that the MoHFW facilitates technical assistance for sub-national levels in implementing disaster management and emergency preparedness measures. However, this support showed some important weaknesses: such as in assisting subnational levels analyze potential vulnerabilities of their health infrastructure in the event of emergencies, preparing risk maps for various emergencies in their areas, or identifying community leaders as part of their emergency preparedness plan (scores $0.21-0.32$ ).

There are also important gaps in the training received by health workers in emergency preparedness and disaster management. Reported gaps include attention to key issues such as food safety after disasters, environmental health after disasters, carrying out rapid needs evaluations, disseminating health information, and ensuring transparency and efficiency in the administration of aid after disasters (scores 0.21-0.32). Coordination gaps were noted: half the respondents reported gaps in coordination of activities even within the health sector, and two-thirds reported gaps in intersectoral coordination. Very few felt that academic institutions are encouraged to include components on emergency preparedness and disaster management in their curricula. It would seem that the emphasis is more on being able to galvanize national resources to respond to political pressure 
when major emergencies occur, but not to building routine competencies for anticipating emergencies and developing early responses to them.

\section{Discussion}

The MoHFW has key roles to play in guiding the nation's public health system: for example by setting national health objectives and priorities, advocacy, developing standards and guidelines, collecting and disseminating information from domestic and international sources, supporting sub-national levels in meeting their own and national health priorities, and providing oversight and quality assurance of public health services.

National studies have suggested that the MoHFW does not fully meet its stewardship roles because it is too involved in direct management of health programs, of the wide range of institutions under its ambit, and other issues such as medical training. ${ }^{15}$ The constitutional separation of health sector activities between center and state have also become blurred in the process, leading to a situation where the MoHFW operates in many ways parallel to the states instead of guiding and supporting them.

This study indicates that the MoHFW could be much more effective in playing its roles in assuring the core public health functions. In the case of many functions, performance could be substantially improved by some relatively minor changes in procedures (Table 3). Figure 1 shows the summary scores for each EPHF, highlighting areas which need more attention. Table 4 summarizes which public health functions are most poorly and best performed, and which are the strong and weak areas across the functions.

Table 4. Worst and best performing functions

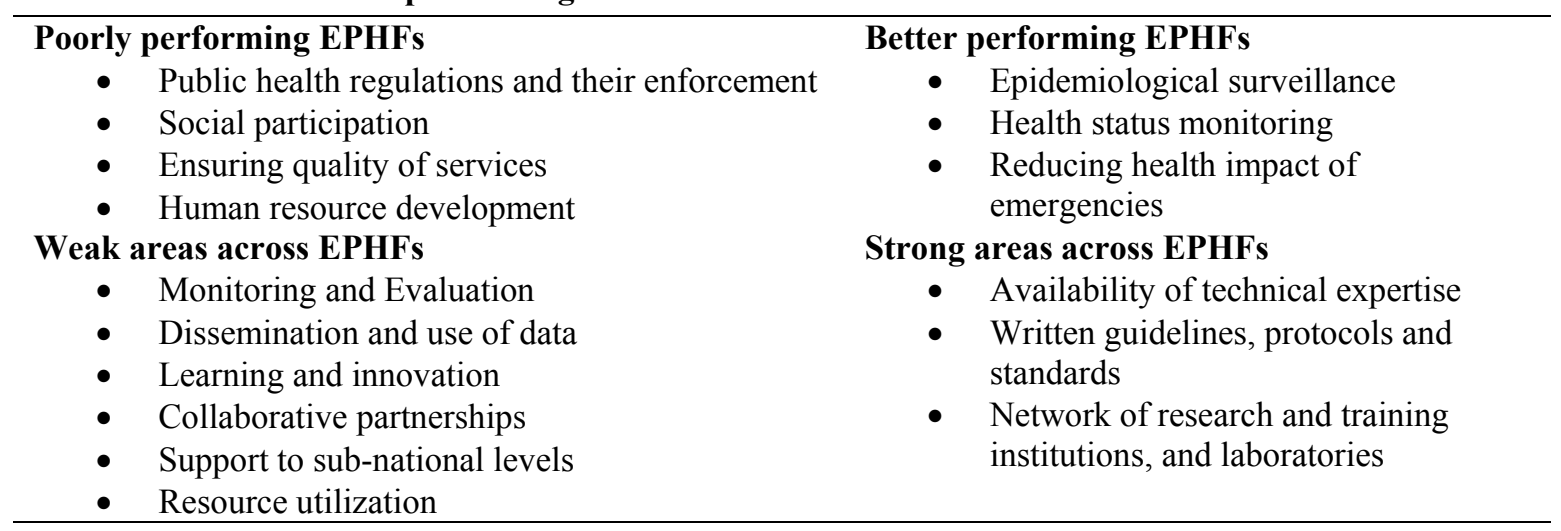

\section{The perceived strengths of the national-level public health system lie in having:}

$\Rightarrow$ The expertise for assessing epidemiological needs, and to respond with appropriate planning and evaluation of actions. Respondents felt that there was adequate capacity to carry out most of the public health functions - except the capacity for tasks relating to public health regulations and their enforcement, and for building partnerships with communities for improving public health.

\footnotetext{
${ }^{15}$ See, for example, Misra et al (2001) and VHAI (1997).
} 
However, other responses suggest that the skills people bring with them may not be well utilized. Respondents gave low scores on human resource development and on fostering public health leadership, and indicated that the views of technical experts are often overlooked. ${ }^{16}$ Skills are also ineffectively used because of isolation from key partners, as discussed below. Other studies indicate that people are too overburdened with routine administration to be able to use their skills. ${ }^{17}$ There seems also to be a shortage of people with public health expertise, as noted by the National Health Policy 2002, although there are substantial reservoirs of skills in medical sciences, statistics, and other technical fields.

$\Rightarrow$ Written guidelines, standards and protocols for almost all the essential functions. However, respondents noted that the MoHFW fails to periodically evaluate and update them, assess their implementation by the respective executive agencies, and take the necessary follow-up action. For example, it developed a model Public Health Act in 1950 and revised it in 1987, but did not use its powerful financial and technical leverage to encourage the states to adopt it.

\section{Perceived obstacles to organizational effectiveness include:}

$\Rightarrow$ Fundamental public health functions are overlooked. Little is being done to establish and enforce public health regulations and sanitary codes - a basic pillar of a public health system. There is also a lack of attention to building social participation, essential for generating public awareness of the issues and demand for better outcomes. There can be little hope of effective disease control while the neglect of public health regulations allows diseases to spawn, and public action is not actively encouraged. Compounding these obstacles in the little attention given to ensuring quality of services, and human resource development. ${ }^{18}$

$\Rightarrow$ Management flaws and poor feedback loops which hinder the effective use of available resources. Program functioning needs to be evaluated regularly, using feedback from all key stakeholders, and methods of monitoring and evaluation need to be improved. Existing evaluations need to be better utilized, even within the MoHFW. Information obtained from evaluations, studies, and other sources needs to be actively disseminated to all potential users, with a view to helping them understand and use it. This information then needs to be used to influence programs and policies. Quality assurance programs need to be put in place. As of now, the organizational culture is perceived to be largely unresponsive to feedback, and unconducive to reassigning its resources as priorities and needs change.

The system needs to be more oriented to seeking ways of using resources more effectively. For example, at least a part of total budgetary allocations could be linked to outcomes, or provided on a competitive basis to those with the most promising

\footnotetext{
16 This last point is also emphasized by Mavalankar (2004).

${ }^{17}$ VHAI (1997), Misra et al (2002), and Mavalankar (2004).

${ }^{18}$ It is interesting to note that these are also the EPHFs and key areas identified to be functioning relatively poorly in the Latin American and Caribbean countries (PAHO, 2002).
} 
proposals. More use also needs to be made of incentive systems: such as those to encourage regulatory enforcement staff to work honestly and correctly, or to encourage health providers to broaden access to their services. Better human resource development policies will help keep staff who are well-qualified at entry from becoming dis-incentivized. At present, there is little perceived use of performance- or outcome-orientation in managing staff and service delivery.

$\Rightarrow$ The MoHFW functions too much in isolation, and needs to form stronger partnerships with other agents involved in assuring public health. As noted above, public health agencies need to work closely with a wide range of partners, because many factors influencing health outcomes are outside their direct jurisdiction. Our study indicates that the possibility of working with communities is largely ignored. The same applies to the private sector despite the fact that it delivers the bulk of outpatient care in the country, and is therefore (at the least) a key ally in obtaining surveillance data and providing essential services. Inadequate use is made even of partnerships with the MoHFW's own research and training institutions to shape staff training programs. ${ }^{19}$

Especially important to address is the current poor performance in working with subnational levels. In a federation of states, the main role of the central government is to support state and local health authorities in their public health planning and implementation, and also ensure that they do not neglect key issues. Unfortunately, the indicator on support to sub-national levels was reported to be very weak in almost all the EPHFs. Greater attention to providing such support would transform the MoHFW's effectiveness.

It is crucial to give health officials and staff opportunities to learn what is entailed in carrying out public health functions effectively. The pattern of responses suggests that people responded positively to broader questions if there were some programs in place associated with a given function - and only when faced with more detailed questions did they note critical gaps in the system (Table 2). Indeed, one of the stated benefits of using the assessment tools (in the United States) is to educate survey participants and raise their "awareness of the many activities related to improving the public's health". ${ }^{20}$

In sum, the system has many strengths, above all good skills and infrastructure. It functions relatively well for services such as responding to disasters, which attract much political and media attention - suggesting that with greater public demand other parts of the system could function equally well. We conclude that with some re-assessment of priorities and revised ways of functioning, health outcomes could be substantially improved. Better public health outcomes are a "win-win" on many fronts: they are good for poor people who are the most exposed to high disease burdens; for improving productivity and growth; and for politicians who support the process.

\footnotetext{
${ }^{19}$ Misra and others (2001:198) suggest that instead of working in partnership with them, the government's present arrangements hamper these institutions' functioning by exercising "excessive control" over them

${ }^{20}$ US Centers for Disease Control http://www.phppo.cdc.gov/nphpsp/NPHPSPOverview.asp
} 


\section{Bibliography}

The word "processed" describes informally reproduced works that may not be commonly available through library systems.

Bettcher, D.W., S. Sapirie, and E.H. T. Goon. 1998. "Essential public health functions: results of the international Delphi study." World Health Statistical Quarterly 51: 44-55.

Center for Policy Research. 1999. "Report on restructuring the ministry of health and family welfare." Chanakyapuri, New Delhi.

Das Gupta, Monica, Peyvand Khaleghian, and Rakesh Sarwal. 2003. "Governance of communicable disease control services: a case study and lessons from India." Policy Research Working Paper 3100. World Bank, Washington, D.C.

David L.H., G.R.S. Rao, A. Upadhyay, and U. Pandey. 1986. "Reorganization: Ministry of Health and Family Welfare." Administrative Staff College of India, Bella Vista, Hyderabad.

Drèze, Jean and Amartya Sen. 1989. Hunger and Public Action, Oxford : Clarendon Press.

Filmer, Deon, Jeffrey S. Hammer, and Lant H. Pritchett. 2000. "Weak Links in the Chain: A Diagnosis of Health Policy in Poor Countries." The World Bank Research Observer 15(2): 199-204.

Government of India, Ministry of Health and Family Welfare. 1996. Report of the Expert Committee on Public Health System. Chaired by Professor J.S. Bajaj. New Delhi: Government of India, Ministry of Health and Family Welfare.

Government of India, Ministry of Health and Family Welfare. 2002. "National Health Policy 2002." Government of India, New Delhi. [Retrieved on September 7, 2004 from http://MoHFW.nic.in/np2002.htm.]

Gupta, Devendra B. 2003. "National agencies and center-state relationships in public health in India." World Bank, Washington, D.C. Processed.

Institute of Medicine. 1988. The Future of Public Health. Washington, D.C.: National Academy Press.

Institute of Medicine. 2002a. The Future of the Public's Health in the $21^{\text {st }}$ Century. Washington, D.C.: National Academy Press.

Institute of Medicine. 2002b. Leadership by Example: Coordinating Government Roles in Improving Health Care Quality. Washington, D.C.: National Academy Press

Institute of Medicine. 2003. Informing the Future: Critical Issues in Health, Second Edition. Washington, D.C.: National Academy Press.

Kaufmann, Daniel, Aart Kraay, and Massimo Mastruzzi. 2003. Governance Matters III: Governance Indicators for 1996-2002. Policy Research Working Paper 3106. World Bank, Washington, D.C. [Retrieved on September 7, 2004 from http://econ.worldbank.org/view.php?type=5\&id=28791.]

Kaufmann, Daniel, and Aart Kraay. 2004. "Governance Matters III: new indicators for 1996-2002 and methodological challenges." Chapter 9 in Transparency International, Global Corruption Report 2004.

Khaleghian, Peyvand, and Monica Das Gupta. 2004. "Public Management and the Essential Public Health Functions." Policy Research Working Paper 3220. World Bank, Washington, D.C.[Retrieved on September 7, 2004 from

http://econ.worldbank.org/view.php?type=5\&id=33192] 
Mavalankar, Dileep. 2004. Study of Technical Top Management Capacity for Safe Motherhood Program in India, Study commissioned by the World Bank, New Delhi (mimeo).

Misra, Rajiv, Rachel Chatterjee, and Sujatha Rao. 2001. "Changing the Indian Health System: Current Issues, Future Directions." Indian Council for Research on International Economic Relations, New Delhi.

National Public Health Partnership (Australia). 2000. National Delhi Study on Public Health Functions in Australia: Report on the Findings." [Retrieved on September 7, 2004 from (http://www.dhs.vic.gov.au/nphp/publications/phpractice/delphi-body.pdf]

Pan American Health Organization (PAHO). 2002. Public health in the Americas: conceptual renewal, performance assessment and bases for action. Washington, D.C.: Pan American Health Organization [Retrieved on September 7, 2004 from http://www.americas.healthsector-reform.org/english/publichealth-americas.htm]

Peters, David H., *Yazbeck, Abdo S.*Sharma, Rashmi R.*Ramana, G. N. V.*Pritchett, Lant H.*Wagstaff, Adam. c2002. Better health systems for India's poor : findings, analysis, and options. Washington, D.C.: World Bank.

http://imagebank.worldbank.org/servlet/WDS_IBank_Servlet?pcont=details\&eid=00009494 6_02051604053640

Pope, Catherine, and Nicholas Mays, eds. 2000. Qualitative Research in Health Care. Bristol, UK: Bmj Publishing Group; 2nd edition.

Public Health Functions Steering Committee. 1994. Public Health in America. (http://web.health.gov/phfunctions/public.htm)

Transparency International. 2004. Global Corruption Report 2004. (http://www.globalcorruptionreport.org/download.htm)

Turnock, B.J., A. Handler, W.W. Dyal, G. Christenson, E.H Vaughn, L. Rowitz, J. W. Munson, T. Balderson, T.B. Richards. 1994. "Implementing and Assessing Organizational Practices in Local Health Departments." Public Health Reports 109 (4): 478-84.

Turnock, Bernard J., and Christopher Atchison. 2002. "Governmental Public Health in the United States; the implications of federalism." Health Affairs 21(6): 68-78.

United Kingdom, Chief Medical Officer. n.d. The Public Health system in England, (http://www.publications.doh.gov.uk/cmo/publichealth/system.htm)

U.S. Centers for Disease Control and Prevention. n.d. National Public Health Performance Standards Program. (http://www.phppo.cdc.gov/nphpsp/NPHPSPOverview.asp)

Voluntary Health Association of India (VHAI). 1990. State of India's Health

Voluntary Health Association of India (VHAI). 1997. Report of the Independent Commission on Health in India.

Yazbeck, Abdo S. and David H. Peters, eds. 2003. Health policy research in South Asia : building capacity for reform. Washington, D.C.: World Bank

World Health Organization. 1999. Removing Obstacles to Healthy Development (http://www.who.int/infectious-disease-report/index-rpt99.html)

World Health Organization. 2002. Public Health Management (http://www.who.int/chronic_conditions/en/PH_management7.pdf)

World Health Organization. 2003. Essential Public Health Functions: a three-country study in the Western Pacific Region. Regional Office for the Western Pacific. 


\section{Appendix 1. Selected List of Central Health Institutions under the MOHFW's Department of Health}

(Note: this list may not be complete, it was taken from the websites of the MoHFW, the ICMR, and WHO-India, and from Misra and others 2001: Appendix 1)

- National Institute of Communicable Diseases, New Delhi

- $\quad$ All India Institute of Hygiene and Public Health, Calcutta

- National AIDS Control Organization, New Delhi

- Central Health Education Bureau

- Central Bureau of Health Intelligence

- Central Research Institute, Kasauli

- Central Drugs Laboratory

- Central Food and Standardisation Laboratory

- Pasteur Institute of India, Coonoor

- National Tuberculosis Institute (NTI), Bangalore

- Indian Council of Medical Research (ICMR), headquartered in Delhi, and under it:

$\Rightarrow 6$ Regional Medical Research Centres

$\Rightarrow 5$ Centres for Advanced Research

$\Rightarrow$ and a slew of permanent research institutes/ centres:

- Malaria Research Centre (MRC), Delhi

- Institute of Pathology (IOP), Delhi

- Institute of Cytology and Preventive Oncology (ICPO), Delhi

- Institute of Research in Medical Statistics (IRMS), Delhi

- Centre JALMA Institute of Leprosy (CJIL), Agra

Rajendra Memorial Research Institute of Medical Sciences (RMRIMS), Patna

National Institute of Cholera and Enteric Diseases (NICED), Kolkata

- National Institute of Occupational Health (NIOH), Ahmedabad National Institute for Research in Reproductive Health (NIRRH), Mumbai

- Institute of Immunohaemotology (IIH), Mumbai

- Enterovirus Research Centre (ERC), Mumbai

- Genetic Research Centre, Mumbai

- National Institute of Virology (NIV). Pune

- National AIDS Research Centre (NARI), Pune National Institute of Nutrition (NIN), Hyderabad

- National Centre for Laboratory Animal Science (NCLAS), Hyderabad

- Food and Drug Toxicology Research Centre (FDTRC), Hyderabad

- Tuberculosis Research Centre (TRC), Chennai

- National Institute of Epidemiology (NIE), Chennai

- $\quad$ Vector Control Research Centre (VCRC), Pondicherry

- $\quad$ Centre for Research in Medical Entomology (CRME), Madurai

- And under the MoHFW's Directorate-General of Health Services: apex hospitals, including medical colleges, nursing schools, pharmacy and dental colleges, public health training institutes, Central Health Service, hospitals and dispensaries, port offices, and Drug Controller's Organization.

- The Central Councils of Health and Family Welfare.

- The Medical Council of India; Dental Council of India; Indian Nursing Council.

- $\quad$ Under the Government of India's Council of Scientific \& Industrial Research (CSIR):

- Central Drug Research Institute, Lucknow

- National Environmental Engineering Research Institute, Nagpur

- 6 zonal laboratories of the National Environmental Engineering Research Institute

- Industrial Toxicology Research Centre, Lucknow 